\title{
Erratum to: Association of Bisphenol A Exposure with Breastfeeding and Perceived Insufficient Milk Supply in Mexican Women
}

\author{
Nicole Kasper $^{1,2}$ - Karen E. Peterson ${ }^{1,3,4}$ - Zhenzhen Zhang ${ }^{1,5} \cdot$ Kelly K. Ferguson $^{6,7}$ • \\ Brisa N. Sánchez ${ }^{5} \cdot$ Alejandra Cantoral $^{8} \cdot$ John D. Meeker $^{6} \cdot$ Maria M. Téllez-Rojo $^{8}$. $^{\circ}$ \\ Carolyn M. Pawlowski ${ }^{9} \cdot$ Adrienne S. Ettinger $^{1}$
}

Published online: 1 July 2016

(C) Springer Science+Business Media New York 2016

\section{Erratum to: Matern Child Health J DOI 10.1007/s10995-016-1974-4}

The original version of this article listed the first author's name as Nicole Kasper-Cusick. It should be Nicole Kasper. This error is now corrected with this erratum.

The online version of the original article can be found under doi:10.1007/s10995-016-1974-4.

Karen E. Peterson

karenep@umich.edu

1 Department of Nutritional Sciences, University of Michigan School of Public Health, 1415 Washington Heights, Ann Arbor, MI 48109, USA

2 Department of Pediatrics, Section of Nutrition, University of Colorado Anschutz Medical Campus, 13123 E. 16th Ave., Aurora, CO 80045, USA

3 Department of Nutrition, Harvard School of Public Health, 665 Huntington Ave., Boston, MA 02115, USA

4 Center for Human Growth and Development, University of Michigan, 300 N Ingalls St., Ann Arbor, MI 48104, USA

5 Department of Biostatistics, University of Michigan School of Public Health, 1415 Washington Heights, Ann Arbor, MI 48109, USA
6 Department of Environmental Health Sciences, University of Michigan School of Public Health, 1415 Washington Heights, Ann Arbor, MI 48109, USA

7 Epidemiology Branch, Department of Health and Human Services, National Institute of Environmental Health Sciences, National Institutes of Health, Research Triangle Park, NC 27709, USA

8 Center for Research on Nutrition and Health, National Institute of Public Health, Universidad No. 655 Colonia Santa Maria Ahuacatitlán, Cerrada Los Pinos y Caminera, C.P. 62100 Cuernavaca, Morelos, Mexico

9 Brandon Newborn Intensive Care Unit, C.S. Mott Children's Hospital, 1540 E Hospital Dr., Ann Arbor, MI 48109, USA 